\title{
Challenges for the Development of Toxic Gas Sensors by Employing Semiconductors and Solid Electrolytes
}

\author{
Yasuhiro Shimizu \\ Graduate School of Engineering, Nagasaki University, Japan \\ shimizu@nagasaki-u.ac.jp
}

\begin{abstract}
The present paper reports at first our recent research work directed to improving $\mathrm{NO}_{2}$ sensing properties of $\ln _{2} \mathrm{O}_{3}$ sensors by controlling pore structure inside $\ln _{2} \mathrm{O}_{3}$ particles by fully utilizing ultrasonic spray pyrolysis of its precursor solution containing a polymer template. Other research results to be pronounced are high $\mathrm{CO}$ sensing performance of two kinds of solid electrolyte gas sensors, potentiometric anion-conducting polymer and NASICON sensors. For both sensors, high CO response and $\mathrm{CO}$ selectivity against $\mathrm{H}_{2}$ at room temperature even in humid environment could be achieved by the compositional design of the sensing electrodes.
\end{abstract}

Key words: $\mathrm{NO}_{2}$ sensor, $\mathrm{CO}$ sensor, $\mathrm{In}_{2} \mathrm{O}_{3}$, Anion-conducting polymer, NASICON

\section{Introduction}

Quick detection of toxic gases, such as $\mathrm{NO}_{2}$ and $\mathrm{CO}$, is of primary importance from the viewpoint of safety in many industrial processes as well as our daily life. We have so far been trying several approaches to improve toxic gas sensing properties. The present paper reports our recent research results on semiconductor $\mathrm{NO}_{2}$ sensors fabricated with porous $\ln _{2} \mathrm{O}_{3}$ powder [1] and solid electrolyte $\mathrm{CO}$ sensors fabricated with an anion-conducting polymer [2] or NASICON [3].

\section{Experimental}

Porous $\ln _{2} \mathrm{O}_{3}$ (pr- $\ln _{2} \mathrm{O}_{3}$ ) powders were prepared by ultrasonic spray pyrolysis of precursor $\ln \left(\mathrm{NO}_{3}\right)_{3}$ aqueous solutions containing given amounts of commercially available or our own synthesizing polymethylmethacrylate (PMMA) microspheres as a template. Microstructure of pr- $-\mathrm{In}_{2} \mathrm{O}_{3}$ was controlled by the size of PMMA microspheres used and the spray pyrolysis conditions [1]. Typical microstructure of $\mathrm{pr}-\mathrm{In}_{2} \mathrm{O}_{3}$ particles is shown in Fig. 1. Thick film sensors were fabricated by screen printing of the pr$\mathrm{In}_{2} \mathrm{O}_{3}$ paste on an alumina substrate equipped with a pair of interdigitated $\mathrm{Pt}$ electrodes, followed by calcination at elevated temperature. $\mathrm{NO}_{2}$ gas response properties were measured in a flow apparatus. The magnitude of $\mathrm{NO}_{2}$ response was defined as the ratio $\left(R_{g} / R_{a}\right)$ of the sensor resistance in $\mathrm{NO}_{2}$ balanced with air $\left(\mathrm{R}_{\mathrm{g}}\right)$ to that in air $\left(R_{a}\right)$.

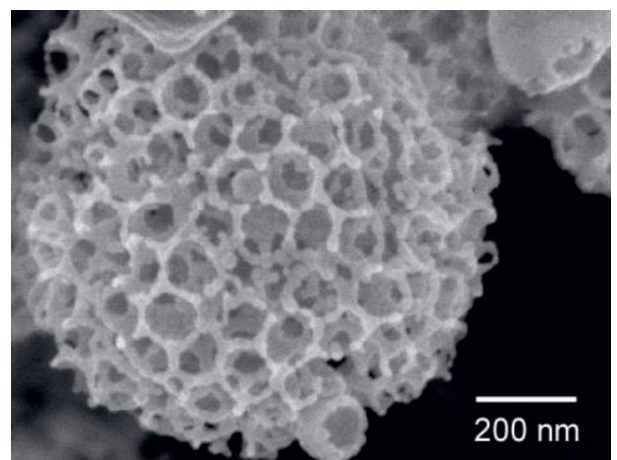

Fig. 1 SEM photograph of pr- $/ n_{2} \mathrm{O}_{3}$ particles.

Anion-conducting polymer (ACP) sensors were fabricated by applying the noble metal-loaded oxide paste, as sensing and counter electrodes, on the surface of both sides of an ACP membrane, followed by drying at $50^{\circ} \mathrm{C}$ in air [2]. The sensor fabricated was sandwiched with $\mathrm{Au}$ meshes as a current collector, and then the electromotive force $(E)$ generated between two electrodes was measured by exposing the sensing electrode to the $\mathrm{CO}$ or $\mathrm{H}_{2}$ sample gases balanced with air at $30^{\circ} \mathrm{C}$, whereas the counter electrode was always kept in air environment. The effect of relative humidity on the $\mathrm{CO}$ response properties was tested.

NASICON-based sensors were fabricated basically by applying both Pt paste mixed with a metal oxide and pristine Pt paste on the same side of the NASICON disc as a sensing and a 
counter electrode, respectively, followed by annealing at $700^{\circ} \mathrm{C}$ in air [3]. The change in electromotive force generated between two electrodes induced by the exposure of both two electrodes to $\mathrm{CO}$ or $\mathrm{H}_{2}$ sample gases from base air was measured under different conditions. The effect of relative humidity on the $\mathrm{CO}$ response properties was also tested.

\section{Results and Discussion}

Figure 2 shows variations in $\mathrm{NO}_{2}$ response and $90 \%$ response time of two kinds of pr- $\ln _{2} \mathrm{O}_{3}$ sensors with operating temperature [1]. Here, pr- $\ln _{2} \mathrm{O}_{3}(1100)$ and pr- $\ln _{2} \mathrm{O}_{3}(1100) \mathrm{S}$ were fabricated with the powders prepared with ca. 77 and $26 \mathrm{~nm}$ diameter PMMA microspheres, respectively, but at the same pyrolysis temperature of $1100^{\circ} \mathrm{C}$. For comparative purpose, results obtained with the sensor (c$\mathrm{In}_{2} \mathrm{O}_{3}(1100)$ ) fabricated with solid $\ln _{2} \mathrm{O}_{3}$ particles prepared without PMMA microspheres, but under the same pyrolysis conditions, are also depicted in the same figure. From the results shown in Fig. 2, we could confirm the usefulness of the introduction of porous structure inside the $\ln _{2} \mathrm{O}_{3}$ particles in enhancing the $\mathrm{NO}_{2}$ response especially around $200^{\circ} \mathrm{C}$, along with improved response time. Further improvement of gas sensing properties may be realized by the simultaneous introduction of mesopores into the skeleton of the macroporous $\ln _{2} \mathrm{O}_{3}$ particles (see Fig. 1).

The ACP sensor $\quad\left\{\mathrm{EC}\left(\mathrm{Au} / \mathrm{SnO}_{2}\right.\right.$ (400air)) $\}$ equipped with $2 \mathrm{wt} \% \mathrm{Au}$ loaded $\mathrm{SnO}_{2}$ (fired at $400^{\circ} \mathrm{C}$ in air) showed high $\mathrm{CO}$ response and excellent $\mathrm{CO}$ selectivity against $\mathrm{H}_{2}$ at $30^{\circ} \mathrm{C}$ even in wet air environment, as shown in Fig. 3, along with acceptable response and recovery behavior. The selection of both the kinds of metal oxides and noble metals used for

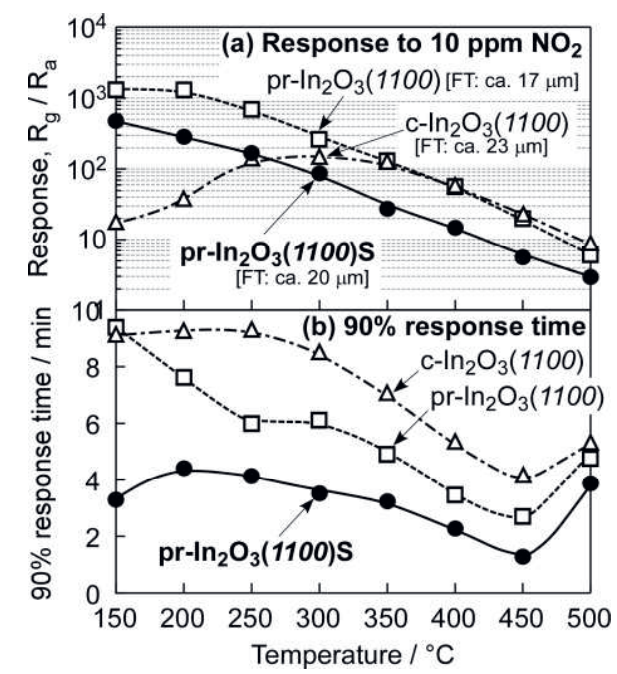

Fig. 2 Variations in (a) response to $10 \mathrm{ppm} \mathrm{NO}_{2}$ and (b) $90 \%$ response time of threel $\ln _{2} \mathrm{O}_{3}$ sensors with operating temeprature. FT: thickness of $\mathrm{In}_{2} \mathrm{O}_{3}$ films.

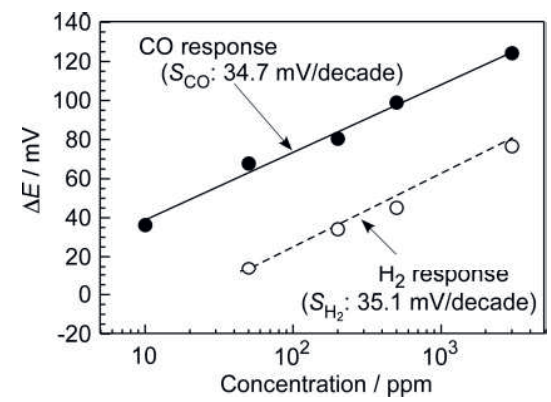

Fig. 3 Concentration dependece of $\mathrm{CO}$ and $\mathrm{H}_{2}$ responses of $\mathrm{EC}\left(\mathrm{Au} / \mathrm{SnO}_{2}\right.$ (400air)) in wet air $(57 \% \mathrm{RH})$ at $30^{\circ} \mathrm{C}$.

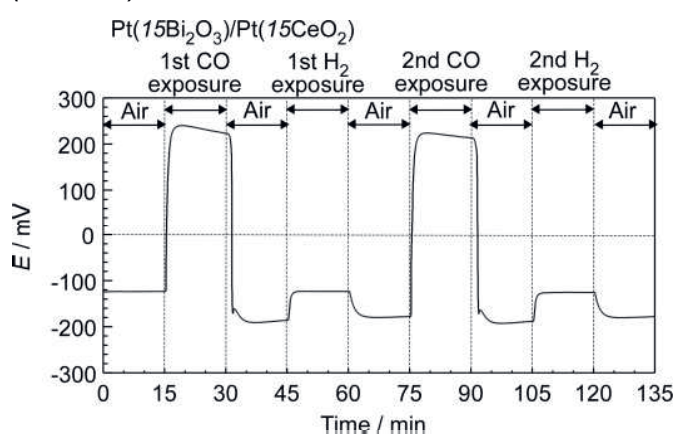

Fig. 4 Response tramsients of $\mathrm{Pt}\left(15 \mathrm{Bi}_{2} \mathrm{O}_{3}\right) /$ $\mathrm{Pt}\left(15 \mathrm{CeO}_{2}\right)$ to $300 \mathrm{ppm} \mathrm{CO}$ and $300 \mathrm{ppm} \mathrm{H}_{2}$ at $25^{\circ} \mathrm{C}$.

electrodes and strict control of their preparation conditions were found to be key factors in determining $\mathrm{CO}$ sensing performance. The measured potential is considered to be determined by the mixed potential resulting from anodic and cathodic reactions.

The direction of a potential shift (positive or negative) of NASICON-based sensors upon exposure to $\mathrm{CO}$ was dependent upon the kind of metal oxides added to the Pt-based sensing electrodes, while the pristine $\mathrm{Pt}$ counter electrode remained unchanged. The positive shift was observed by the addition of $\mathrm{Bi}_{2} \mathrm{O}_{3}$ or $\mathrm{La}_{2} \mathrm{O}_{3}$, but the negative shift in the case of $\mathrm{CeO}_{2}$ or $\mathrm{V}_{2} \mathrm{O}_{5}$. By considering these results, we could realize much improved $\mathrm{CO}$ response and then $\mathrm{CO}$ selectivity against $\mathrm{H}_{2}$ with the sensor $\left\{\mathrm{Pt}\left(15 \mathrm{Bi}_{2} \mathrm{O}_{3}\right) / \mathrm{Pt}\left(15 \mathrm{CeO}_{2}\right)\right\}$ equipped with $15 \mathrm{wt} \%$ $\mathrm{Bi}_{2} \mathrm{O}_{3}$ added $\mathrm{Pt}$ sensing and $15 \mathrm{wt} \% \mathrm{CeO}_{2}$ added $\mathrm{Pt}$ counter electrodes, as shown in Fig. 4. Other pronounced futures of this type of sensors will be delivered in the presentation.

\section{References}

[1] T. Hyodo, E. Fujii, K. Ishida, T. Ueda, Y. Shimizu, Sens. Actuators B, 244, 992-1003 (2017); doi.:10.1016/j.snb.2017.01.091

[2] T. Hyodo, T. Goto, T. Ueda, K. Kaneyasu, Y. Shimizu, J. Electrochem. Soc., 163, B300-B308 (2016); doi.: 10.1149/2.0561607jes

[3] T. Ueda, H. Takeda, K. Kamada, T. Hyodo, Y. Shimizu, Electrochemistry, 85, 1-5 (2017); doi.: 10.5796/electrochemistry.85.174 